\title{
EUS-guided choledocoduodenostomy and gastroenterostomy to palliate simultaneous biliary and duodenal obstruction due to pancreatic cancer $\square$
}

Endoscopic management of simultaneous biliary and duodenal malignant obstructions can be challenging. Traditionally, duodenal and biliary stentings have been used [1,2].

We review the case of a 45-year-old male who presented with jaundice and weight loss. Abdominal computed tomography (CT) showed a $3.4-\mathrm{cm}$ mass at the head of the pancreas resulting in biliary obstruction without liver metastasis ( $\mathbf{V i}$ deo 1).

Endoscopic ultrasound (EUS)-guided fine-needle aspiration was consistent with locally advanced pancreatic adenocarcinoma. Endoscopic retrograde cholangiopancreatography could not be performed due to severe duodenal stricture proximal to the ampulla.

Using EUS, the common bile duct $(2.6 \mathrm{~cm})$ was punctured from the duodenal bulb with a $19 \mathrm{G}$ needle. Cholangiogram was obtained and a wire was passed (\Fig. 1). Hot Axios (1-cm diameter) was deployed followed by a 3-cm, 7F double pigtail stent ( $\mathbf{F i g . 2}$ ).

Six days later, the patient started vomiting. An upper gastrointestinal imaging series demonstrated a duodenal stricture with reflux of contrast through Axios to the biliary tree.

A pediatric endoscope was able to traverse the duodenal stricture. It was used to distend the targeted jejunal loop with contrast and methylene blue. An echoendoscope (introduced on the side of the pediatric endoscope) was able to identify the targeted jejunal loop ( $\mathbf{F i g . 3}$ ). A 2cm-diameter Hot Axios was deployed. The stent was dilated to $2 \mathrm{~cm}$ ( Fig.4, - Fig.5).

The procedure was uneventful.

CT demonstrated a successful gastroenterostomy (\$ Fig.6).

In conclusion, EUS-guided choledochoduodenostomy/gastroenterostomy can be considered as an alternative treatment for duodenal/biliary stenting in pa-
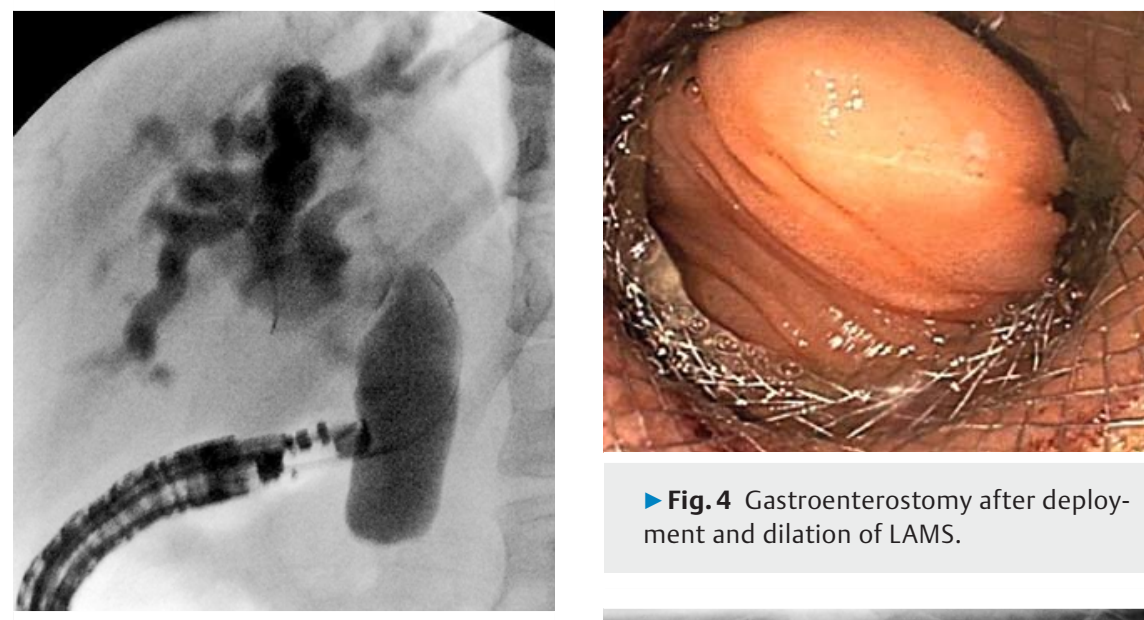

Fig. 4 Gastroenterostomy after deployment and dilation of LAMS.

- Fig. 1 EUS-guided cholangiogram.

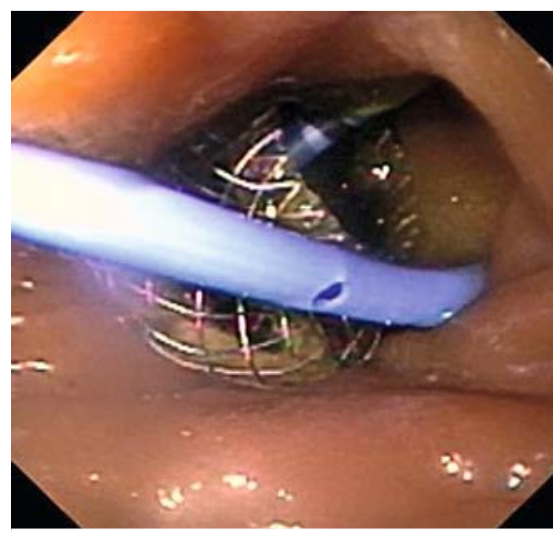

- Fig. 2 Choledochoduodenostomy after deployment of LAMS and double pigtail stent.

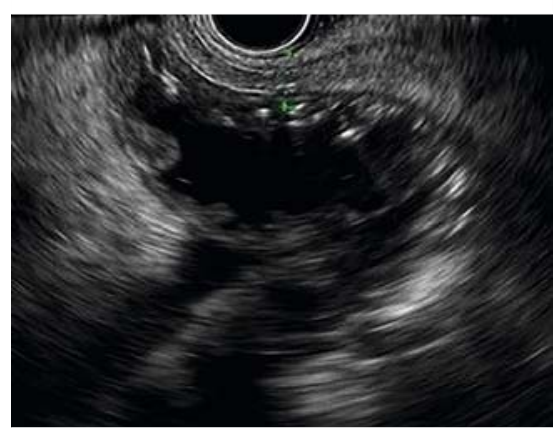

- Fig. 3 EUS image of target jejunal loop.

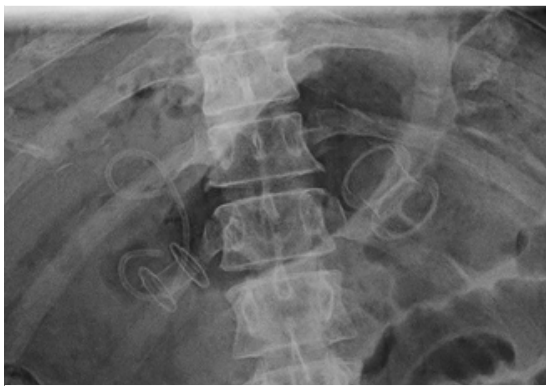

- Fig. 5 X-ray image of choledochoduodenostomy and gastroenterostomy stents.

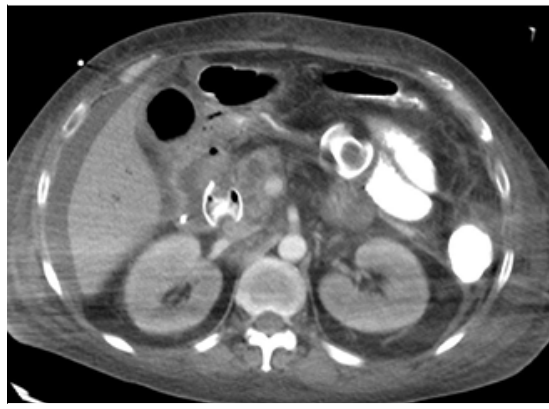

- Fig. 6 CT image of choledochoduodenostomy and gastroenterostomy stents. 


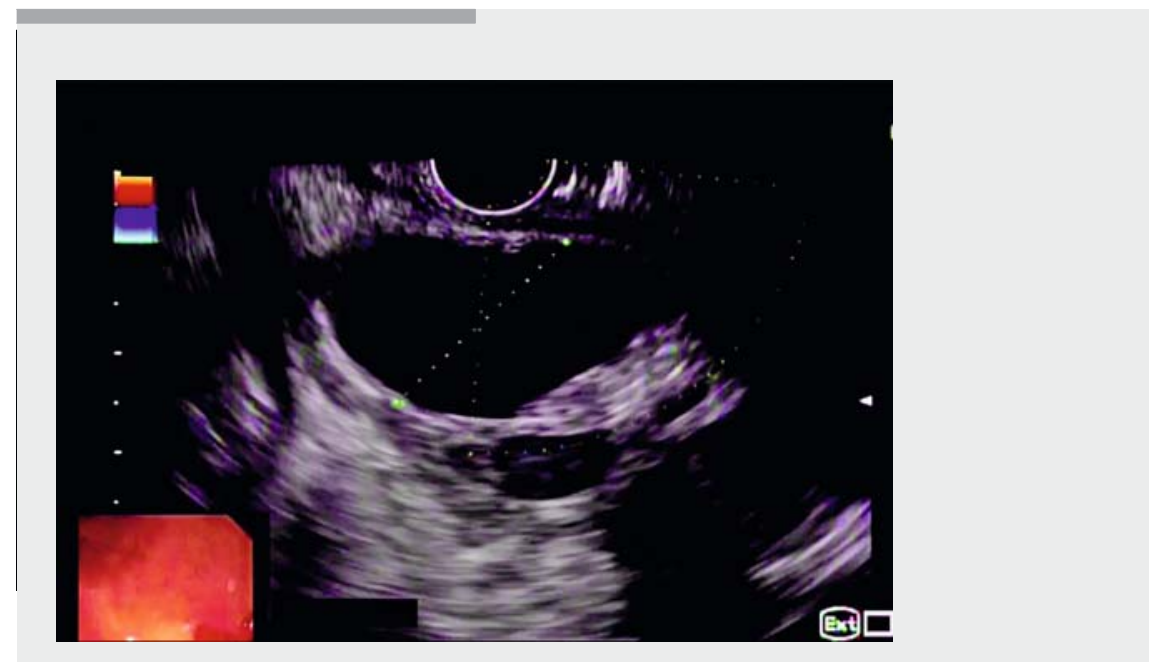

\section{Bibliography}

DOI http://dx.doi.org/10.1055/a-1236-3540

Endoscopy International Open 2020; 08: E1681-

E1682

Georg Thieme Verlag KG

Rüdigerstraße 14,

70469 Stuttgart, Germany

eISSN 2196-9736

(C) 2020. The Author(s).

This is an open access article published by Thieme under the terms of the Creative Commons Attribution-NonDerivative-NonCommercial License, permitting copying and reproduction so long as the original work is given appropriate credit. Contents may not be used for commecial purposes, or adapted, remixed, transformed or built upon. (https://creativecommons.org/licenses/by-nc-nd/4.0/)

Video 1 EUS-guided Choledochoduodenostomy and gastroenterostomy to palliate biliary and duodenal obstruction due to pancreatic cancer.

\section{(๑) $\odot \odot$}

tients with combined biliary/duodenal malignant strictures types I \& II [1]. This technique allows for easier future access to the biliary tree. In addition, duodenal stenting has a higher rate of reintervention than gastroenterostomy [3].

\section{Competing interests}

The authors declare that they have no conflict of interest.

The author

\section{Michael Lajin}

Sharp Grossmont Hospital, La Mesa, California, United States
Corresponding author

\section{Michael Lajin}

8860 Center Drive Suite 330, La Mesa,

California 91942, USA

Fax: +1-619-4605148

mlajin@yahoo.com

\section{References}

[1] Mutignani M, Tringali A, Shah SG et al. Combined endoscopic stent insertion in malignant biliary and duodenal obstruction. Endoscopy 2007; 39: 440-447

[2] Baron TH. Management of simultaneous biliary and duodenal obstruction: the endoscopic perspective. Gut Liver 2010; 4: S50

[3] Phillip SG, Young JY, Dong W et al. EUSguided gastroenterostomy versus enteral stent placement for palliation of malignant gastric outlet obstruction. Surg Endosc 2019; 33: 3404-3411 